\title{
Effect of amino acids on inhibition of lactate dehydogenase-X by gossypol
}

\author{
Masood H. Javed ${ }^{1,3}$ and Mehtab A. Khan ${ }^{2}$ \\ 1 Department of Biochemistry, The Aga Khan University, Karachi, \\ Pakistan \\ 2 Aero Medical Institute, PAF Base, Masroor, Karachi, Pakistan. \\ 3 Corresponding author: Fax, (92) 51-446879; \\ E-mail, scm@sihl.sdnpk.undp.org \\ Accepted 13 January 1999
}

Abbreviations: $A A$, amino acids; AGE, agarose gel electrophoresis; $B S A$, bovine serum albumin; EEO, electroendosmosis; GAA, gossypol acetic acid; LDH, lactate dehydrogenase; NBT, nitro blue tetrazolium; PMS, phenazine methosulfate; SDSPAGE, sodium dodecyl sulfate polyacrylamide gel electrophoresis

\begin{abstract}
Gossypol acetic acid (GAA) has been shown to have male antifertility effects, but there are pronounced differences among animal species. In the search of endogenous effector molecules, which interfere with the functions of GAA, we have studied the in vitro effect of various amino acids on the inhibition of the purified LDH-X by GAA. Histidine, cysteine and glycine were shown to block the effect of GAA. The effects of these amino acids were concentration dependent. Histidine and glycine protection was found to be complex type in which both the $\mathrm{Km}$ and Vmax were decreased compared to control. Arginine, glutamic acid, phenylalanine and valine were found to be ineffective against the inhibitory action of GAA.
\end{abstract}

Keywords: amino acids, goat, gossypol acetic acid, LDH-X, testes.

\section{Introduction}

Gossypol is a yellow polyhydroxylated phenolic compound that occurs in roots and seeds of Malvaceae, a family of cotton. Three forms of this compound, gossypol, gossypol acetic acid (GAA) and gossypol formic acid (GFA) exist in nature (Qian, 1984). Several investigators, particularly in China, Austria and Brazil, have shown antifertility effects of all these forms in males (Qian, 1984; Morris et al., 1986; Zhi Ping et al., 1990). The antifertility properties of gossypol are associated specifically with the (-)-isomer (Morris et al., 1986). There are clear differences among animal species in their sensitivity to the antifertility action of gossypol. Among the laboratory animals tested, hamsters seemed to be the most sensitive, followed by rats, monkeys and dogs in decreasing order, while rabbit and mice appeared to be insensitive (Wang et al., 1979; Hahn et al., 1981; Morris et al., 1986). The sensitivity of GAA towards rat testes showed marked individual variations. Long-term treatment might cause complete atrophy of the semniferous epithelium in some of the animals and sterility is the likely consequence of this condition (Dai et al., 1980; Qian, 1984).

Although the mechanism(s) of antifertility effects of GAA are not known, it has been suggested that it inhibits LDH (Gupta et al., 1988). LDH-X is a sperm specific and used as an antigen to induce infertility in female mice (Singh et al., 1994). It has been shown that immunization of male mice with LDH-X impaired fertilization (Mahi-Brown et al., 1990). Similarly, LDH-X shows higher activity in patients showing oligospermia and genital tract infection (Virji, 1985). Thus it seems that LDH-X is more relevant to the reproductive functions as compared to other isoenzymes of LDH. LDH-X is one of the many regulatory enzymes involved in the metabolic processes needed for sperm motility and the absence of this isoenzyme may contribute infertility in men (Gavella and Cvitovic, 1985). The differential effects of GAA on various animal species suggest that certain endogenous molecules modulate the inhibitory effects of GAA on LDH. In our previous report (Javed and Waqar, 1995), we observed that the inhibition of LDH-5 by GAA in rat liver which was blocked by the presence of histidine in the reaction mixture. We therefore undertook this study to demonstrate that some other amino acids might also block the inhibitory action of GAA on LDH-X from goat testes which can be easily purified in large quantity.

\section{Materials and Methods}

\section{Materials}

GAA, NADH, amino acids, sodium pyruvate, and agarose type-1 low electroendosmosis (EEO) were from Sigma Chemical Company (St. Louis, USA). Colchicine-CHSepharose was a gift from Dr. Tomoji Kocha (Department of Hygienic Chemistry, Showa College of Pharmaceutical Sciences, Tokyo, Japan). All other chemicals were of analytical grade.

\section{Purification of LDH-X}

All purification procedures of $\mathrm{LDH}-\mathrm{X}$ were performed at $4{ }^{\circ} \mathrm{C}$, otherwise indicated. Fresh goat (Capra hircus) testes 
were obtained from local slaughterhouse and transported to the laboratories on ice. These were frozen at $-20^{\circ} \mathrm{C}$ until use. Frozen testes were thawed and homogenized in 10 volumes of cold distilled water. After filtration through cheesecloth and centrifugation at $10,000 \mathrm{~g}$ for $30 \mathrm{~min}$, the supernatant was heated for 10 minutes at $55^{\circ} \mathrm{C}$ to destroy all LDH isoenzymes except LDH-X (Gupta et al., 1988). This was again centrifuged at $10,000 \mathrm{~g}$ to remove precipitated proteins. $\mathrm{LDH}-\mathrm{X}$ from this supernatant was purified to homogeneity by ammonium sulfate fraction-ation, colchicine- $\mathrm{CH}$ sepharose column chromatography and again by heating at $65^{\circ} \mathrm{C}$ for $30 \mathrm{~min}$. The detailed methods have already been published elsewhere (Javed at et., 1995; Javed et al., 1997). The LDH isoenzymes were separated by agarose gel electrophoresis (Javed et al., 1995; Javed et al., 1997) and visualized with a staining solution specific for LDH activity. The solution is freshly prepared in $20 \mathrm{mM}$ Tris- $\mathrm{HCl}$ buffer $(\mathrm{pH} 8.5)$ contained $0.75 \mathrm{mM} \mathrm{NAD}^{+}, 94 \mathrm{mM}$ lithium lactate, $0.37 \mathrm{mM}$ nitro blue tetrazolium (NBT) and $0.008 \mathrm{mM}$ phenazine methosulfate (PMS). After electrophoresis the gels were immersed in the staining solution at $37^{\circ} \mathrm{C}$ in the dark for about $10 \mathrm{~min}$. The stained gels were fixed in $5 \%$ acetic acid and photographed.

\section{Enzyme and protein assays}

Enzyme activity was measured at $25^{\circ} \mathrm{C}$ in a reaction mixture containing $50 \mathrm{mM}$ potassium phosphate buffer, $0.18 \mathrm{mM} \mathrm{NADH}, 0.6 \mathrm{mM}$ sodium pyruvate $(\mathrm{pH} 7.5)$ and appropriate amount of enzyme to obtain a measurable decrease in absorbance at $340 \mathrm{~nm}$ using Ames RA50 photometer. One unit of the enzyme was defined as the amount of enzyme that produced one mmole of $\mathrm{NAD}^{+}$per minute under our assay conditions (Javed et al., 1995;
Javed et al., 1997). $K_{m}$ and $V_{\max }$ values were calculated from initial velocity measurements, using Enzifitter (RJ Leather-barrow), a non-linear regression program that integrates the data into the Michaelis-Menton equation with simple weighting (Javed et al., 1995; Javed et al., 1997). Proteins were determined by the method of Lowry et al. (1951) with BSA as standard.

For inhibition studies, $5 \mathrm{mM}$ GAA was dissolved in ethanol. Three $\mathrm{ml}$ of this solution was incubated with about 0.3 units $/ \mathrm{ml}$ enzyme in $50 \mathrm{mM}$ phosphate buffer containing $0.6 \mathrm{mM}$ pyruvate, $\mathrm{pH} 7.5$ for about $20 \mathrm{~min}$ at $25^{\circ} \mathrm{C}$. Three $\mathrm{ml}$ ethanol served as control. The volume of the incubation mixture was $800 \mathrm{ml}$. The reaction was started with $200 \mathrm{ml}$ of $0.9 \mathrm{mM}$ NADH. Pyruvate was added in the incubation mixture because it has been shown (Gupta et al., 1988) that it did not protect the inhibition of GAA on LDH. To observe the effect of amino acids on GAA inhibition, the enzyme (0.3 units $/ \mathrm{ml})$ was incubated with GAA in the presence or absence of different concentrations of amino acids. The volume of incubation mixture was again $800 \mathrm{ml}$. The $\mathrm{pH}$ of all amino acid solutions was adjusted to 7.5. The results are expressed as remaining activity (as \%) compared to control (100\%). The nature of protection by some amino acids (glycine and histidine) was determined by using LineweaverBurk plots of the data obtained in the presence of varied concentration of pyruvate or NADH. When the reaction was studied for different concentrations of $\mathrm{NADH}$, then the reaction was started with $200 \mathrm{ml}$ of desired concentration of $\mathrm{NADH}$.

\section{Results}

Figure 1 confirms the purification of LDH-X from goat testes. It has already been confirmed by using SDSPAGE that the colchicine-sepharose affinity

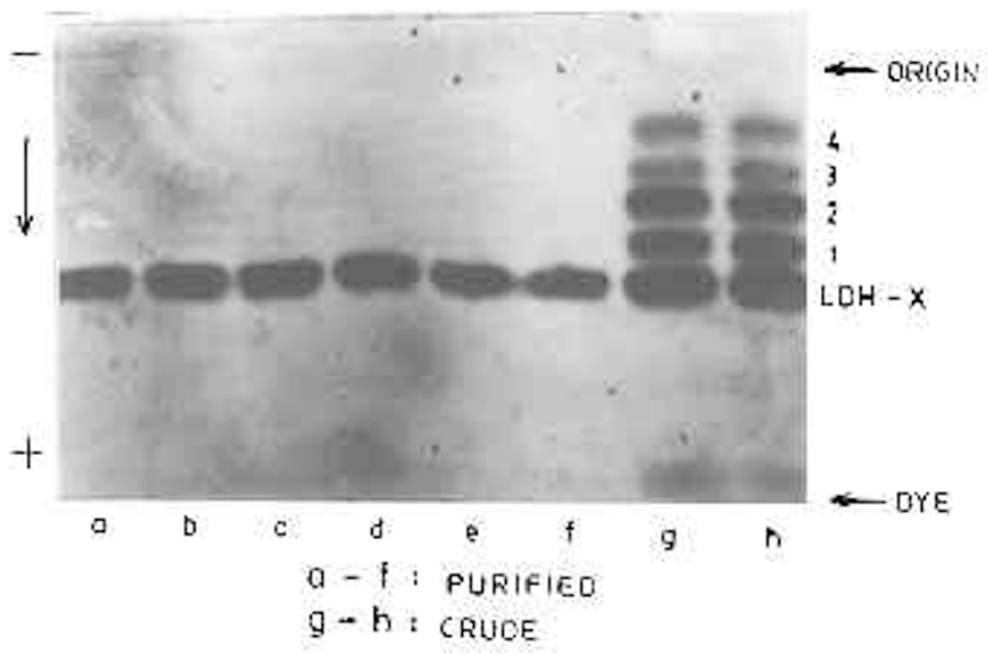

Figure 1. Agarose gel electorphoresis (AGE) of $L D H$ from goat testes. Samples $(2 \mathrm{ml})$ were applied on $1 \%$ horizontal agarose gel and subjected to electrophoresis for $1 \mathrm{~h}$ at $4^{\circ} \mathrm{C}$. The LDH isoenzymes were detected as described in the 'Materials and Methods'. a-f, purified LDH-X; g-h, crude testes homogenate. 
Table 1. Effect of amino acids on the action of GAA on LDH-X. The amino acid at desired concentration was incubated with $\mathrm{LDH}-\mathrm{X}$ in the presence of $20 \mathrm{mM} \mathrm{GAA}, 0.18$ $\mathrm{mM} \mathrm{NADH}$ and $50 \mathrm{mM}$ phosphate buffer ( $\mathrm{pH} 7.5)$ and kept at room temperature for about $20 \mathrm{~min}$. The control 'a' group was without GAA and amino acid but contained 3 $\mathrm{ml}$ ethanol, while the control ' $b$ ' contained only $20 \mathrm{mM}$ GAA. The activity of the enzyme was performed as described in the 'Materials and Methods'. The values are shown in \% as average of three separate determinations.

\begin{tabular}{|c|c|c|c|c|c|c|}
\hline \multirow[b]{2}{*}{ AAs } & \multirow[b]{2}{*}{ 'a' } & \multirow[b]{2}{*}{ 'b' } & \multicolumn{4}{|c|}{$\begin{array}{l}\text { Concentration of amino acids } \\
(\mathrm{mM}) \text { in the incubation mixture }\end{array}$} \\
\hline & & & 25 & 50 & 75 & 100 \\
\hline Gly & 100 & 35 & 40 & 79 & 84 & 104 \\
\hline His & 100 & 35 & 48 & 67 & 80 & 104 \\
\hline Cys & 100 & 27 & 35 & 65 & 86 & 104 \\
\hline Phe & 100 & 39 & 32 & 36 & 41 & 41 \\
\hline Val & 100 & 44 & 43 & 39 & 43 & 46 \\
\hline Arg & 100 & 43 & 50 & 43 & 44 & 49 \\
\hline Glu & 100 & 43 & 42 & 40 & 40 & 49 \\
\hline
\end{tabular}

Figure 2. Lineweaver-Burk plots of LDH-X in the control (-), in the presence of GAA ( $\mathbf{\square - \square})$, and in both GAA and glycine (O-O). LDH-X activity was measured in the presence of $0.18 \mathrm{mM} \mathrm{NADH}$ as described in the 'Materials and Methods'. The values are average of three separate experiments. Inset: effect of pyruvate concentration on the activity of LDH. The symbols are identical as in the main figure. chromatography completely purifies the total LDH (Kocha et al., 1990; Javed et al., 1995; Javed et al., 1997). Figure 1 shows that the crude extract of testes showed five $\mathrm{LDH}$ isoenzymes (Lanes, $\mathrm{g}-\mathrm{h}$ ). The fast moving isoenzyme was considered as LDH-X (Camp and Sande, 1988) which has been shown to be heat resistant (Gupta et al., 1988) while all other isoenzymes (LDH-1 to LDH-4) were heat-labile (lanes, a-f). The specific activity of the purified LDH-X was about 400 units/mg protein.

When LDH-X was preincubated with GAA in the presence of amino acids, histidine, cysteine and glycine, these amino acids strongly blocked the inhibitory effect of GAA. The protection was concentration dependent (Table 1). However, arginine, glutamic acid, phenylalanine, and valine had no protective effect, even at $100 \mathrm{mM}$ (Table 1)

When we checked the nature of protection by some amino acids, glycine and histidine, both showed complex type of kinetics with GAA (Figures 2 and 3). At lower concentrations of pyruvate, glycine increased the initial velocity $(v)$ but at higher concentration of pyruvate the glycine has decreased the $V_{\max }(43 \mathrm{mmol} / \mathrm{min})$ as compared to control $(91 \mathrm{mmol} / \mathrm{min}$ ) and inhibited (Figure 2). Similarly, the histidine also increased the ' $v$ ' at lower concentrations of NADH but again it decreased the

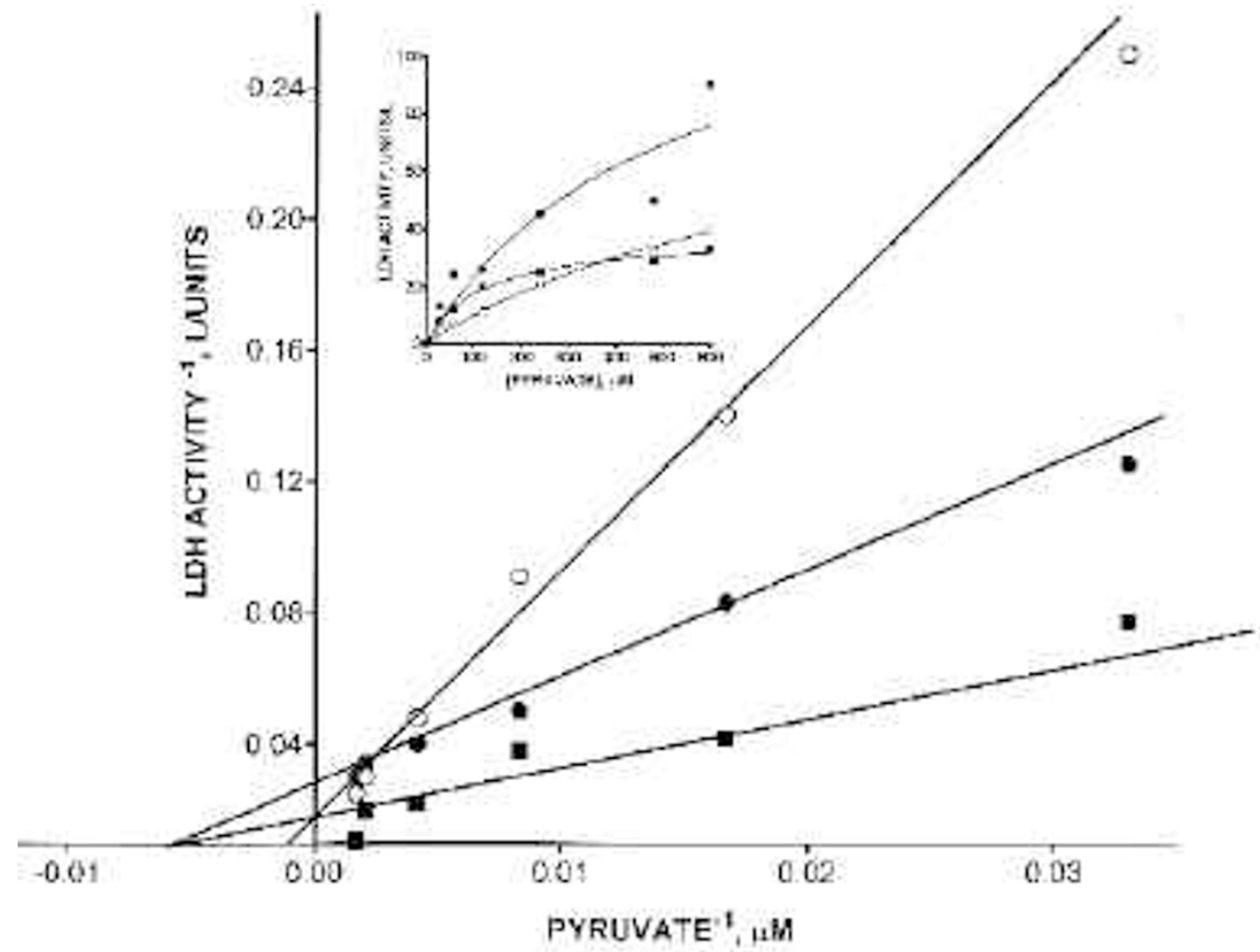




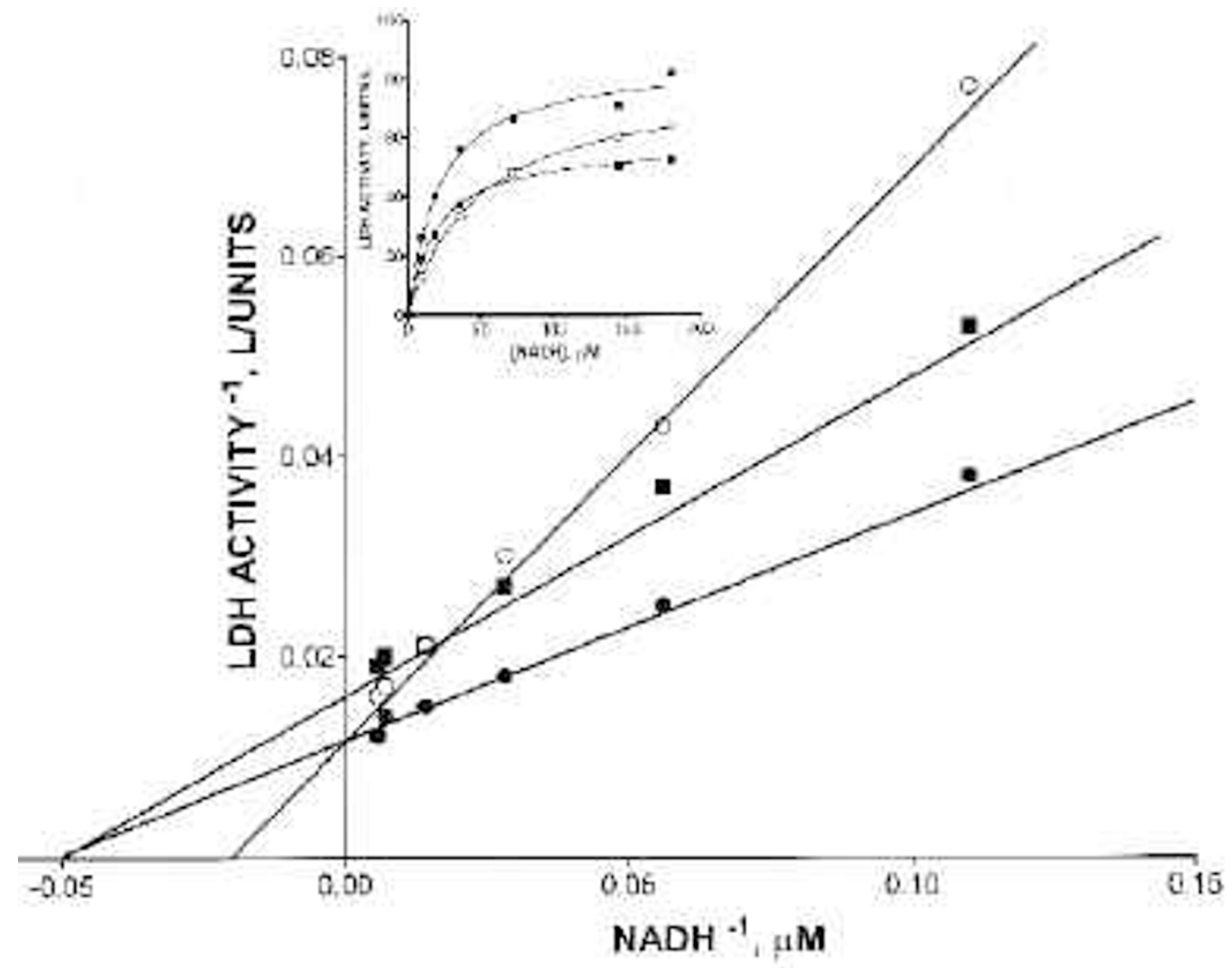

Vmax $(63 \mathrm{mmol} / \mathrm{min})$ at higher concentration of $\mathrm{NADH}$, compared to control (83 mmol/ $\mathrm{min}$ ) (Figure 3).

\section{Discussion}

There are pronounced differences among animal species in their sensitivity to the action of GAA as a male antifertility agent (Qian, 1984; Morris et al., 1986; Javed and Waqar, 1995). These differences may be due to some endogenous molecules that may block the antifertility effects of GAA in certain unresponsive species. In our previous work (Javed and Waqar, 1995), we have shown that the inhibitory effect of GAA on LDH-5 from rat liver was blocked by histidine. The present study also showed that the inhibitory action of GAA on LDH-X was also blocked by other amino acids (Table 1). However, at higher concentrations of substrates (pyruvate and NADH), the Vmax was also decreased in the presence of glycine or histidine in the reaction mixture, which indicates more inhibition, although $\mathrm{Km}$ was decreased. This indicates that at higher substrate concentrations, these amino acids might
Figure 3. Lineweaver-Burk plots of LDH-X in the control (-) GAA ( $-\square)$ and in both GAA and histidine (O-O). The pyruvate concentration in the reaction mixture was $0.6 \mathrm{mM}$. The values are averages of three separate experiments. Inset: effect of NADH concentration on the activity of LDH. The symbols are identical as in the main figure.

form some dead-end complex with the enzyme-GAAsubstrate complex. In this way free concentration of both enzyme and GAA is decreased. Since the $\mathrm{Km}$ is decreased as compared to $\mathrm{Km}$ in the presence of GAA (Figures 2 and 3), this indicates that both glycine and histidine compete for the binding sites of GAA on LDH$\mathrm{X}$. As the $\mathrm{Km}$ of control group and $\mathrm{Km}$ in the presence of amino acids are almost same (Figures 2 and 3), the binding sites for these amino acids and pyruvate or NADH on $\mathrm{LDH}-\mathrm{X}$ are mutually exclusive. Thus, it seems that glycine and histidine, somehow remove the GAA from binding sites on LDH-X and this site is then available for pyruvate. Morris et al. (1986) have shown that in the presence of human serum albumin or poly-L-lysine but not lysine, the human and hamster $\mathrm{LDH}-\mathrm{X}$ were protected 
from GAA. The protective role of human albumin was found to be due to its strong binding with GAA (Morris et al., 1986). Thus free concentration of GAA was too much less in the reaction mixture compared to the added GAA. At present we are unable to explain why some amino acids protect the LDH-X from GAA inhibition while others do not. We do not know the binding behavior of GAA with individual amino acids that may affect the functions of GAA in the body.

It is also difficult for us to explain the physiological significance of these complex effects of amino acids on reversal effect against GAA inhibition on LDH-X. The contradictory effect of GAA on various animals as an antifertility compound may partly be due to the different intracellular concentrations of various amino acids in their testes. The effect of other amino acids and their detailed kinetic behavior with inhibitory action of GAA on $\mathrm{LDH}-\mathrm{X}$ will be more useful and is in process.

\section{References}

Camp, K. V. and Sande, M. V. (1988) LDH isoenzymes in prostate and testis of wild animals and some histological remarks. Urol. Res. 16: 373-375

Dai, R. X. and Pan, S. Y. (1980) Studies on the antifertility effect of gossypol. VI. Observations of testicular atrophy of rats administered gossypol for long terms. Acta. Expt. Biol. Sonica. 13: 192-199

Gavella, M. and Cvitkovic, P. (1985) Semen LDH-X deficiency and male infertility. Arch. Androl. 15: 173-176

Gupta, G. S., Kapur, S. and Kinsky, R. G. (1988) Inhibition kinetics of LDH isoenzymes by gosspol acetic acid. Biochem. Int. 17: 25-34

Hahn, D. W., Rusticus, C., Homn, R. and Johnson, A. N. (1981) Antifertility and endocrine activities of gossypol in rodents. Contraception 24: 97-105

Javed, M. H. and Waqar, M. A. (1995) Protective effect of histidine by inhibition of gossypol on rat's liver LDH-5. Biochem. Soc. Trans. 23: 626S

Javed, M. H., Yousuf, F. A, Hussain, A. N., Ishaq, M. and Wqar, M. A. (1995) Purification and properties of LDH from liver of Uromastix hardwickii. Comp. Biochem. Physiol. 111B: $27-34$

Javed, M. H., Azimuddin, S. M. I., Hussain, A. N., Ahmed, A. and Ishaq, M. (1997) Purification and characterization of LDH from varanus liver. Exp. Mol. Med. 31: 25-30

Kocha, T., Fukuda, T., Isobe, T. and Okuyama, T. (1990) Large scale purification of bovine brain lactate dehydrogenase by affinity chromato-graphy on immobilized colchicine. J. Biochem. 107: 138-143

Lowry, O. H., Rosenbrough, N. J., Farr, A. L. and Randall, R. (1951) Protein measuement with folin phenol reagent. J. Biol. Chem. 193: 265-275

Mahi-Brown, C. A., Vandervoort, C. A., Mcguinness, R. P., Overstreet, J. W., O'Hern, P. and Goldberg, E. (1990) Immunization of male but not female mice with the spermspecific isoenzyme of lactate dehydrogenase $\left(\mathrm{LDH}-\mathrm{C}_{4}\right)$ impairs fertilization in vivo. Am. J. Reprod. Immunol. 24: 1-8

Morris, I. D., Haggins, C. and Matlin, S. A. (1986) Inactivation of testicular LDH-X from laboratory animals and man by gossypol and its isomers. J. Reprod. Fert. 77: 607-612

Qian, S. Z. (1984) Gossypol: a potential antifertility agent for males. Ann. Rev. Pharmacol. Toxicol. 24: 329-360

Singh, P. P., Singh, V .N. and Sirmour, S. K. (1995) Estrogen dependent LDH-Y, a new $\mathrm{LDH}$ isozyme and fertility factor in mice uterus during early pregnancy. Horm. Metab. Res. 27: 182-184

Virji, N. (1985) LDH-C4 in human seminal plasma and its relationship to testicular function: methodological aspect. Int. J. Andrology 8: 193-200

Wang, Y. E., Luo, Y. D. and Tang, X. C. (1979) Studies on the antifertility action of cotton seed meal and gossypol. Acta Pharm. Sinica 14: 662-669

Zhi-Ping, G., Yi-Xing, W., Goo-Wei, S., Wei-Chang, W., Zhen-Xing, C., Xiu-Juan, Z., Qin-Xiang, S. and Yu, J. (1990). Relationship between hormone profiles and the 